\title{
Tuva Türkçesinde Başlık Kısaltmalar ve Karmalar¹
}

\section{İlker TOSUN²}

\author{
$\ddot{\mathbf{O} z}$
}

\begin{abstract}
Her dil, değişen sosyal koşullar nedeniyle yeni kelimelere ihtiyaç duyar. Her dilin kendine has yeni kelime türetme yolları vardır. Türk dilinde söz yapımında başlıca şu yollar kullanılmaktadır: türetme, geri türetme, birleştirme, örnekseme, ödünçleme, tekrar ödünçleme, çocuk dili, halk etimolojisi, doğrudan kopyalama vb. Kısaltmalar, Türk dilinde diğer dillere kıyasla yaygın bir kelime türetme yolu değildir. Kısaltmalar, başlık kısaltma, karma ve kırpma başlıkları altında incelenebilir. Başlık kısaltma kişi, kurum ve diğer kavramları oluşturan isimlerin ilk harflerinden oluşturulur: NATO (North Atlantic Treaty Organisation). İki ayrı sözcüğün kısaltılarak tek bir kavramda ifade edilmesine karma adı verilir: Eurovision (European Televison). Kırpma ise bir sözcüğün bir parçasının atılması yolu ile yeni sözcük türetmektir: demo (demonstration). Tuva Türkçesi Türkiye Türkçesine göre genç bir yazı dili olarak kabul edilebilir. Tuvalar 20. yüzyılın başından beri Rus hâkimiyeti altında yaşamaktadır. Sovyetler Birliği döneminde Tuva Türkçesine komünizm ile ilgili pek çok kısaltmalar girmiştir. Biz bu bildiride Tuva Türkçesinde yer alan bazı kısaltmalar inceleyeceğiz.
\end{abstract}

Anahtar kelimeler: Tuva Türkçesi, söz yapımı, kısaltma, kırpma, karma, Sovyetler Birliği.

\section{Acronyms and Blendings in Tuvan Turkish}

\begin{abstract}
Every language needs new words due to changing social conditions. Each language has its own ways of deriving new words. In Turkish language, there are some ways of word formation: derivation, backformation, compunding, analogy, borrowing, reborrowing, children language, child language, folk etimology, calque etc. Abbreviations are not a common way of deriving new words in Turkish language compared to other languages. Abbreviations consist of clipping, blending and acronyms. Certain constructions formed by taking and combining the initial letters of words that are either names of persons, organizations or objects are called acronyms: NATO (North Atlantic Treaty Organisation). Blends are deliberate formations in which the compund words are blended by removing at least one element of the orginal segments: Eurovision (European Televison). Clipping is the word formation process which consist in the reduction of a word to one of its parts: demo (demonstration). Tuva language can be regarded as a young writing language compared to Turkish language. The Tuvans have been living under Russian domination since the early 2oth century. During the period of the Soviet Union, a plenty of abbreviations about communism entered the Tuvan language. In this paper, we will examine some of the abbreviations in Tuvan Turkish.
\end{abstract}

Key words: Tuvan Turkish, word formation, abbreviation, clipping, blending, Soviyet Union.

Bildirinin Tuva Türkcesinde Akronimler olan adı, konu karmaları da kapsayacak sekilde genisletildiği için değiștirilmiştir. Dr. Öğr. Üyesi, Kırklareli Üniversitesi, Fen Edebiyat Fakültesi, Çağdaş Türk Lehçeleri ve Edebiyatları Bölümü, ilkertosun@yandex.com.tr [Makale kayıt tarihi: 4.6.2018-kabul tarihi: 15.8.2018] 


\section{Giriş}

Dilbilimi çalışmalarında dilin ön plana çıkarılan özelliklerinden birisi de bir dizge (system) oluşudur. "Ögeleri ya da bölümleri çeşitli ilkeler uyarınca birbirine bağlı düzenli bütün, yapı" (Vardar 2002: 79) olarak izah edebileceğimiz "dizge" kavramı, dili oluşturan ve çeşitli işlevlere sahip olan ögelerin rastlantısal değil, belirli ve tutarlı kurallar çerçevesinde bir araya geldiğini vurgulamaktadır. Temel işlevi "bildirişim" olan bu sistem, toplumsal koşullar çerçevesinde şekillenir, dış etkilere açıktır ve her düzeyde (fonetik, morfolojik, sentaktik, semantik vs.) değişir ve gelişir. Literatürde "canlılık" olarak adlandırılan bu özelliği nedeniyle dil, beliren değişikliklere ayak uydurabilmek için birtakım "yeni ögelere" ihtiyaç duyar.

"Dildeki türetme kurallarına uygun olarak yaratılmış olan yeni birimler (İmer 2011: 270) 3 olarak tanımlayabileceğimiz yeni ögeleri (neologism) karşılamak için diller, tarihsel süreçte birtakım yollar oluşturmuşlardır. Bu yolların en üretken olanları o dilin kendi karakteristik yapısıyla ilgili olanlar iken, daha az üretken yollar ise çeşitli dil ilişkileri nedeniyle sonradan edinilmiştir. Bir dilde yeni ögelerin oluşma süreci, dilbilimi çalışmalarında "söz yapımı" (Tuv. sös çogaadılgazı, Rus. slovoobrazovaniye İng. word formation / word manufacture) başlı̆̆ı altında incelenmektedir. Türk dilinde söz yapımında kullanılan yollar, şu şekilde sıralanabilir:

Ekleme (affixation): susturucu, bildirme, gözle-.

Birleştirme (compounding): bilinçaltı, işveren.

Ödünçleme (borrowing): kitap, duvar, iskele.

Yerlileştirme (folk etymology): gardolap, yediemin.

Örnekseme (analogy): gelenek, seçenek.

Tür değiştirme (convertion): uydu, çlktı.

İkileme (reduplication): ağlaya ağlaya, er geç, yorgun argın.

Uydurma (coinage): nezaket, emniyet, sorun, ödev, görev.

Titremleme (intonation): bodru'm / Bo'drum, karta'l / Ka'rtal.

Genelleşme (generalization): Danzig > daniska; Bordeaux > bordo; Gilette > jilet.

Geri oluşum (backformation): öykü>öykünmek

Derleme ve tarama (compiling and scan): abartma, asalak, aşama, atamak.

Eksiltme (elipsis): düdüklü tencere > düdüklü; yazma eser > yazma.

\section{Kisaltma}

a) Başharflileştirme4 (acronym): TDK, AVM, ODTÜ.

b) Karma (blending): sunta, arge.

3 Dilde yeni ögelerin ne olabileceği konusunda araștırmacılar arasında farklı görüșler bulunmaktadır. Ferdi Bozkurt, bu farklı bakış açllarını Cabré ve Matore’un geliştirdiği parametreler üzerinden vermektedir. Cabré’ye göre yeni ögeler: a) Eğer bir birim son zamanlarda ortaya çıkmışsa yeni ögedir. b) Eğer bir birim sözlükte yer almıyorsa yeni ögedir. c) Eğer bir birim biçimsel veya anlamsal istikrarsızlık sergiliyorsa yeni ögedir. ç) Eğer bir birim konuşucu tarafindan yeni bir birim olarak algılanıyorsa yeni birimdir. Matore'a göre yeni ögeleri: Tamamen yeni bir sözcük (yeni yaratım, ses taklidi, dilin türetme olanaklarıyla yapılan türetimler, özel bir addan alınanlar, ölü ya da yaşayan bir dilden ödünçlemeler); 2. Halen kullanılmakta olan bir sözcüğe yeni bir anlam yüklenmesi; 3. Dil bilgisel kategorilerde oluşan değişiklikler (örneğin çok uzun bir zaman sıfat olarak kullanılan "ideal" sözcüğünün 1830'dan sonra isim olarak kullanılmaya başlanması) gibi (Bozkurt, 2017: 42, 43).

4 Akronimler, Türkiye Türkolojisinde "başlık kısaltma" olarak da isimlendirilmektedir. Biz çalışmamızda bu terimi kullanmayı tercih ettik. 
c) Kurpma (clipping): foto(ğraf), santim(etre), milim(etre), (Akalın 2015: 831-841).

Türk dilinde gerek tarihsel dil alanlarında, gerek çağdaş Türk lehçelerinde üretken söz yapımı yolları ekleme, birleştirme ve ödünçleme olarak karşımıza çıkmaktadır. Ancak 20. yüzyılın ikinci yarısından sonra, özellikle İngilizce gibi Batı dillerinde oldukça işlek olarak kullanılan kısaltmalar, çağdaş Türk lehçelerinde de kendisine yer bulmaya başlayan söz yapımı yollarındandır.

Bu bildiride öncelikle kısaltma kavramının ortaya çıkışı, kullanım sebepleri ve türevleri üzerinde durulacak, sonrasında Tuva Türkçesinde sözlükselleşerek sözlük birimler haline gelen ve çeşitli yapım ekleri ile kendilerinden yeni sözcükler türetilen başlık kısaltmalar ve karmalar, söz yapımı bağlamında ele alınacaktır.

\section{Kisaltma Kavramı}

Dilbilimi sözlüklerinde "Konuşma ve yazışmalarda sık kullanılan sözlerin veya özel adların değişik ve anlaşılır biçimde kısaltılarak kullanılması" (Karaağaç 2013: 534); "Bir sözcüğü ya da dizimi daha kısa duruma getirme" (İmer 2011: 175), "Stk kullanılan kelimelerin, şahıs, yer ve kuruluş adlarının yer kazanmak, kolaylık sağlamak gibi pratik gayelerle yazıda kısaltılmış şekli” (Korkmaz 1992: 102) olarak tanımlanan kısaltmalar, tarihin erken dönemlerinden itibaren farklı kültürlere ve dönemlere ait metinlerde görülebilmektedir.

İlk Sümer kil tabletlerinde ve erken Yahudi metinlerinde (MILH < Mi Iolh Lnv Hshmilh "Bizim için cennete kim gidecek?”, Cannon 1989: 99, 100) örneklenen kısaltmalar, ilerleyen dönemlerde özellikle pragmatik gayelerle daha sık kullanılmaya başlamıştır. Süheyla Bayrav, Eski Yunanlıların hem zamandan hem parşömenden tasarruf etmek ve daha hızlı yazmak için çeşitli yazılı materyal üzerinde kısaltmalar kullandığını, Romalılar döneminde kısaltma kullanımının yaygınlaştığını5 (S.P.R. "Senatus Populusque Romanus), eski Hristiyanların yasaklamalar döneminde dinlerini gizlemek için çeşitli metinlerde kısaltmalara başvurduklarını söylemektedir. Bayrav, ünlü Romalı hatip Cicero'nun kölesi Tullius Tiro'nun bulduğu ve zaman içerisinde büyük gelişme gösteren stenografinin (Yun. Stenios (kısa)+ takhos “çabuk”) uzun müddet Avrupa'da kullanıldığını ifade etmektedir (Bayrav 1998: 76-77).

Kısaltmalar, ciddi, titiz ve düzenli olarak tutulan Osmanlı vesikalarında da karşımıza çıkmaktadır. Said Öztürk, "Osmanlı Arşiv Belgelerinde Siyakat Yazısı ve Tarihi Gelişimi” adlı eserinde cumadeyn (cemaziyülevvel ve cemaziyülahır ayları), masar (muharrem, sefer ve rebiyülevvel), recec (rebiyülahir, cemaziyülevvel, cemaziyülahır), reşen (receb, şaban, ramazan) gibi kısaltmalara yer vermektedir (Öztürk 1994: 267-283). Süer Eker, Besim Atalay'dan bu konu ile ilgili şunları aktarmaktadır: "Osmanlılar döneminde yılbaşı muharrem ayında başlar ve asker maaşları her üç ayda bir verilirdi. Muharrem, safer ve rebiyülevvel aylarının maaşlarına "masar ulufesi”, receb, şaban ve ramazan aylarının maaşlarına "reşen ulufesi”, rebiyülevvel, cemaziyülevvel, cemaziyülahır maaşlarına "recec ulufesi” ve diğer ayların maaşlarına da aynı şekilde "lezez ulufesi” adı verilirdi (Eker 2009: 366).

Avrupa dillerinde, diğer dillere kıyasla daha yaygın olan kısaltmalar, özellikle 15. asırdan sonra daha da yaygınlaşmış, bu nedenle çağdaş sözlüklerde görülen kısaltma listeleri dönem sözlüklere girmeye ve ayrıca sadece kısaltmaları ihtiva eden sözlükler yayımlanmaya başlamıştır. Garland Cannon, "Abbreviations and Acronyms in English Word-Formation" adlı yazısında Avrupa dillerinde Modus Legendi Abbrevituras (1475?), Lexicon Diplomaticum (1745), Manuel Tironien (1775), Dictionnaire des

5 Latince kısaltmalar günümüzde İngilizcede de kullanılmaya devam etmektedir: A.D. Anna Domini "in the year of our Lord", s.f. sub finem "near the end". bkz. Partridge 2006: XV, XVII. 
Abreviations (1846) gibi sözlüklerden günümüzdeki sözlüklere gelinceye kadar kısaltmaların madde başı olarak sayılarının giderek arttığını vurgulamaktadır (Cannon 1989: 100, 101).

Ancak kısaltmaların katbekat artarak kullanılmaya başlaması, 20. yüzyılda yaşanan "Bilgi Patlaması" (The Information Explosion) ile ilgilidir. Bu dönemde çeşitli bilim dallarında büyük bir sıçrama yaşanması, sonuç olarak teknolojinin giderek gündelik hayata daha fazla girmesi, kitle iletişiminde hızın büyük önem kazanması nedeniyle, gerek resmi dilde, gerek dilin gündelik kullanımlarında kısaltma ve türevlerinin yaygınlaşmasını sağlamıştır. Özellikle teknik bilimlerde kısaltmalar, bilimsel jargonun en önemli unsurları haline gelmiştir. Örnek vermek gerekirse en yaygın tıp sözlüklerinden biri olan 'Jablonski's Dictionary of Medical Acronyms and Abbreviations'ta 32.60o'den; bilgisayar teknolojileri kısaltmalarını ihtiva eden 'Dictionary of Computer Acronyms and Abbreviations'ta 38.0oo'den; hukuk terimlerini içeren 'Index to Legal Citations and Abbreviations'ta 37.00o'den fazla başlık kısaltmanın yer alması, İngilizcedeki kısaltmaların yoğunluğunu belirgin bir şekilde gösterecektir.

Ruhan Gül, Rusçada özellikle sosyal bilimlerin toplum mühendisliği için çok etkin olarak kullanıldığı Sovyetler Birliği döneminden itibaren günümüze kadar giderek artan kısaltmaların sayısını "sokr.ru" adlı siteden hareketle 153.00o'in üzerinde vermektedir (Gül 2017: 488). Cannon; Crowley ve Sheppard'ın 1987 yllında yayımlanan "Gale's Acronyms, Initialism and Abbreviations Dictionary" adlı sözlüğünde ise 400.00o’i aşkın madde başı olduğunu bildirmektedir (Cannon 1989: 101). Hüseyin Yıldız, Türkçedeki kısaltmaları incelediği çalışmasında 2005 yılında basılan Yazım Kılavuzu'nda 578 kısaltmanın olduğunu, Türkiye'de hazırlanmış kısaltma sözlüklerinin Avrupa dilleri ile kıyaslandığında çok cılız kaldığını ifade etmektedir (Yıldız 2010: 259).

Yukarıda zikredildiği gibi özellikle Batı dillerinde çeşitli nedenlerle gerek bilimsel alanlarda, gerek gündelik hayatta yaygınlaşan, sözlüklerde madde başı olarak yer alan veyahut müstakil sözlükleri hazırlanan kısaltmaların zamanla birtakım alt dalları oluşmuştur. Batı alan yazınında isimlendirilişi ile ilgili birtakım farklılıklar olmakla beraber, kısaltmalar "alphabetism", "initialism" veya "abbreviations" başlıkları altında incelenmektedir (Bauer 2004: 15).

Genel olarak kısaltmalar türlerine göre şöyle şemalaştırılabilir:

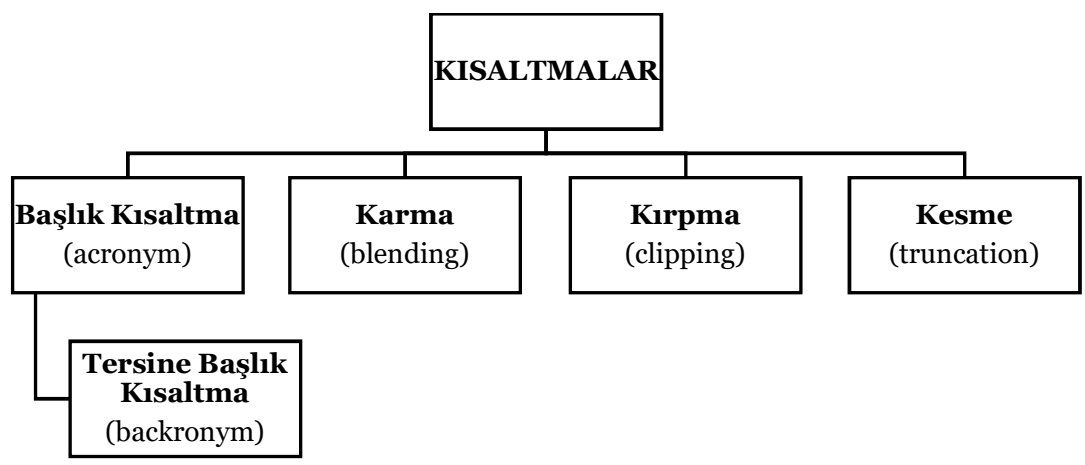

\section{Başlık Kisaltma (Acronym):}

Tüm dünya dillerinde en yaygın kısaltma türlerinden biri olan başlık kısaltmalar, uluslararası literatürde "acronym" (Eski Yunanca: akros "son, uç" + onym "isim”, bkz. Hendrickson 2008: 7) olarak adlandırılır. Bir kavramı, bir kurumu, bir özel adı ifade eden sözcüklerin ilk harfleri bir araya getirilerek yapılan başlık kısaltmaların özellikleri şu şekilde sıralanabilir: 
Başlık kısaltmalar kimi zaman büyük harflerin (AIDS “acquired immune defciency syndrome”), kimi zaman da küȩük harflerin sıralanması ile (laser "light amplification by stimulated emission of radiation") yapılmaktadır.

Bazı başlık kısaltmaları bir kelime gibi telaffuz edilebilir: jpg “jipeg” (Baueer 2004: 12).

Başlık kısaltmalar bazen başka kısaltmaları içerecek biçimde oluşturulabilir: ACT-UP "AIDS coalition to unleash power" (Bussmann 2006: 1).

Başlık kısaltmalar kimi zaman örtmece olarak karşımıza çıkmaktadır: WC "water closet” (su dolabı, tuvalet), (Gelderen 2006: 235).

S. Rajimwale, 'Handbook of Linguistic Terms'te Modern İngilizcenin karakteristik bir özelliği olarak nitelediği başlık kısaltmaların bilimsel ve teknolojik jargonda bolca bulunduğunu ve özellikle büyük şehirlerde gençler arasında çok popüler olduğunu vurgulamaktadır (Rajimwale 2006: 2). Bussmann başlık kısaltmaların birer sosyolekte dönüşmesini şöyle izah eder: Kısaltmalar yeni sözcük türetmenin çok üretken bir yoludur. Her gün sosyal medyada yeni sözcükler icat edilir: dink "double income/no kids", nimby "not in my backyard (Bussmann 2006: 1). Sosyal medyanın yanı sıra kısa mesaj yazımında (SMS) da çok sayıda başlık kısaltmanın kullanıldığı görülmektedir6: OMG “Oh My God” (Aman Tanrım), idk “I don’t know” (Bilmiyorum), imho “in my humble opinion” (Benim düşünceme göre), 4EAE "For Ever, And Ever" (Sonsuza dek), J4F "Just For Fun” (Sadece eğlence için), LOL "Laughing Out Loud” (Yüksek sesle gülmek), HAND “Have A Nice Day” (İyi Günler)7.

Başlık kısaltmalar, Türkiye Türkçesinde son zamanlarda yaşanan toplumsal gelişmeler nedeniyle sosyal hayatta yaygınlaşmaya başlamıştır: HGS “Hızlı Geçiş Sistemi”, KGS (Kartlı Geçiş Sistemi), AVM (Alış Veriş Merkezi), İHA (İnsansız Hava Aracı), SİHA (Silahlı İnsansız Hava Aracı), TOMA (Toplumsal Olaylara Müdahale Aracı).

Başlık kısaltmaların halk etimolojisi içerisinde değerlendirilebilecek kullanımları da mevcuttur. "backronym" olarak adlandırılan bu kullanımlar, başlık kısaltmalara çeşitli nedenlerle asıl anlamından farkl anlamlar yüklemek olarak tanımlanabilir. Örnek olarak Stalin döneminde, gizli siyasi polis teşkilatının başlık kısaltması olan OGPU'nun açılımı "Ob'edinennoe Gosudarstvennoe Politicheskoe Upravlenie", halk arasında "O, Gospodi, pomogi ubezhat'!” (Oh, Tanrım Kaçmama Yardım Et!, Kotljarchuk, Sundstrom 2017: 180); Edirne Belediyesi Otobüs İşletmelerinin kısaltması ise halk arasında EBOİ’nin açılımı, "Enayi Biner Oturmadan İner” şeklinde yapılması gösterilebilir.

\section{Karma (Blending):}

Karma sözler (blend, amalgam, hybric, telescoped, portmanteau word) genellikle iki kelimenin bazı bölümlerinin bir araya getirilmesi ile elde edilen yeni sözcüklerdir. Günlük dilde kullanılan bazı sözcükler bu yolla oluşturulduğu gibi kimi ticari isimler de bu yolla türetilmiştir: Bollywood "Bombay+wood" (Hendricson 2008: 103); brunch "breakfast+lunch", fantabuluous "fantastic+fabulous" (Malmkjær 2002: 361); paradrop "parachute+drop", chocobar

\footnotetext{
$6 \quad$ Kısaltmalar her ne kadar yazılı iletisime hız kazandırsa da coklukla yanlıs bilgilendirmeye (misinformation) veya gönderilen yazılı veya sözlü iletinin anlaşılamamasına neden olabilmektedir. Örnek olarak uzay yürüyüşüne çıkan bir astronotun "SD" kısaltmasının ne anlama geldiğini bilmemesi gösterilebilir: http://www.dailymail.co.uk/news/article5743137/Incredible-moment-NASA-astronaut-realizes-hes-left-memory-card-HOME-spacewalk.html

İngilizcede SMS'lerde kullanılan çok sayı kısaltma için bkz. Erişim Tarihi: 25.04..2018: https://www.thefreelibrary.com/A+glossary\%3a+usage+abbreviations+of+mobile+phone+SMS.-a0347004730
} 
"chocolate+bar", moped "motor+pedal" (Rajimwale 2006: 39); Eurovision "European Plus Television", metrosexual "metropolitan+sexual", Gestapo "Geheime Staatspolizei" (Gizli Devlet Polisi), (Campbell 1999: 275); Singlish "Singapore+English", Japlish "Japan+English" (Richards, Schmidt 2002: 55).

Türkiye Türkçesinde yoğun olarak kullanılan kimi karmalar şöyle örneklenebilir: arge "araştırma+geliştirme", Avrasya "Avrupa+Asya" (Demirci 2015: 62); albay "alay+bay", orgeneral "ordu+general” (Eker 2009: 366), OHAL (Olağanüstü Hal), AKBİL (Akıllı Bilet). KALEKOL (Kale+ (Kara)kol), BİMER (Başbakanlık İletişim Merkezi), CİMER (Cumhurbaşkanlığı İletişim Merkezi).

\section{Kurpma (Clipping):}

Kısaltmanın bir alt dalı olan kırpmalarda bir sözcüğün bir bölümü atılarak yine aynı kavram ifade edilebilmektedir: kilo < kilogram; İbo < İbrahim, pop < popular (Eker 2009: 367), santim < santimetre, motor $<$ (motosiklet).

Gazete yazılarında sık kullanılan bu kısaltma türü gençlerin arasında ve argoda oldukça yaygındır. Kırpmalar genellikle şu yollarla oluşturulur (Rajımwale 2006: 46):

Kelimenin ilk hecesi atılarak yapılanlar phone $<$ telephone, plane $<$ aeroplane;

Kelimenin son hecesi atılarak yapılanlar: doc $<$ doctor, photo $<$ photograph;

Kelimenin hem başından hem de sonundan hece atılması ile yapılanlar: flu < influenza, fridge "refrigerator" (Rajımwale 2006: 46), e-mail < electronic mail, Show-biz $<$ Show business, gym < gymnasium, hippo < hippopotamus, çello $<$ violoncello, ammo $<$ ammunition, limo $<$ limousine (Campbell 1999: 278).

\section{Kesme (Truncation):}

Kesme olarak isimlendirebileceğimiz bu kısaltmalar, dil tarihindeki en eski kısaltma türü olarak karşımıza çıkmaktadır. Süheyla Bayrav, Latince metinlerde çok sayıda özel isim olduğunu, bunları yazarken yanılmak imkanı bulunmayan isimlerin sadece ilk harflerinin yazıldığını (Caius yerine, C., Lucius yerine L; Marcus yerine M.) belirtmektedir (Bayrav 1998: 76). Hüseyin Yıldız, TDK yazım kılavuzundan hareketle kitap, dergi, yön adları, element ve ölçülerin uluslararası kısaltmaları, unvanlar, mahalle, cadde, sokak gibi yerleşim yerlerinin adları, çeşitli bilim dallarındaki terimlerin kesme yönetimi ile kısaltıldığını ifade etmektedir: Fe "demir", Gen. "general", kim. "kimya”, Prof. "profesör", cm "santimetre”, İng. "İngilizce" vb. (Yıldız 2010: 261) ${ }^{8}$.

\section{Tuva Türkçesinde Kısaltmalar}

Tuva Türkçesi, Türkiye Türkçesi ile kıyaslandığında oldukça genç bir yazı dili olarak karşımıza çıkar. Türkiye Türkçesi, Eski Türkçe döneminden itibaren farklı tarihsel dönemlerde ve alanlarda kesintisiz olarak devam edegelmiş bir yazı geleneğinin devamıdır. Castrén, Radlof ve Katanov’un çeşitli derlemelerle belgelediği Tuva Türkçesinin yazı dili oluşu ise 20. yüzyılın ilk yarısında gerçekleşmiştir.

Bildirimiz kısaltmaları söz yapımı bağlamında ele aldığı için Tuva Türkçesindeki kesme türünden kısaltmalar ele alınmayacaktır. 
Kubilay Han dönemine kadar Türk kağanlıkları tarafından yönetilen bölge, 1768-1912 yılları arasında Çin Mançu Hanedanına bağlı olarak idare edilmiş; 1912 yllında bu hanedanın yıkılışından sonra Tuva'nın ileri gelenleri ülkelerinin kaderini belirlemek için yol arayışlarına girişmişlerdir. Nitekim Tuvalı aydınlar 29 Ekim 1913 yılında Rus çarı II. Nikolay’a bir mektup yazarak Rus himayesine girmek istediklerini bildirmiş ve bu başvurunun sonucu olarak Tuva bölgesi 4 Nisan 1914’te Çarlık korumasına alınmıştır. Ekim Devrimi’nden sonra ise Tuvaların Kurucu Meclisi (Ündezilekçi Hural), Sugbajı kötünde 300 kişilik heyet ile toplanarak 13 Ağustos 1921'de Tıva Arat Respublika'yı (Tuva Halk Cumhuriyeti) kurmuşlardır (Darbaa 2010: 39, 40, 47-49).

1921-1930 yılları arasında dini-kültürel sebepler ve coğrafi yakınlık nedeniyle resmi yazışmalarda (doktaal "tutanak"; dürüm "kanun”, şınzılga "rapor"; Salzınma, Sat 1980: 41) ve Ünen gazetesinde9 yazı dili olarak Moğol dilini ve alfabesini (Eski Uygur alfabesi) kullanan Tuvalar, bu yıllarda bir alfabe arayışı içerisindedir ve kültürel nedenlerle 1930 yılına kadar Moğol yazısını (Mool bijik) kullanmaya devam etmişlerdir. 20 Ekim-10 Kasım 1929'da toplanan Tuva Halk Cumhuriyetinin Devrimci Partisi TARN (TAPH, Tıva Arattın Rebolyustug Namı) yeni alfabe için Sovyetler Birliğinden yardım istemiş ve bu istek üzerine S. E. Malov'un başkanlığını yapıtığı heyetle, içinde E. D. Polizanov, A. N. Suhotin, N. F. Yakıvlev, L. D. Pokrovskiy, K. A. Aleverdov'un yer aldığı iki ayrı heyetin hazırlamış olduğu alfabeler, A. A. Palmbah tarafından birleştirilmek suretiyle Tuva Türkçesi için Latin temelli bir alfabe hazırlanmıştır (Arıkoğlu 1997: 155-156). 28 Haziran 1930 yllnda kabul edilen Latin esaslı Tuva alfabesinin ömrü ancak 11 yl olmuş, 1941 yllında şimdi de kullanılan Kiril alfabesine geçilmiştir.

Bu nedenle Tuva Türkçesi yazı dilinde, dil etkileşimleri açısından Moğolca ve Rusçanın etkisi büyüktür. Moğolca sözler, uzun bir tarihsel süreçte kültürel nedenlerle Tuva Türkleri arasında yaygınlaşmış ve günümüzde de hem yazı dilinde hem de sözlü dilde kullanılmaya devam eden sözlerdirio Rusçadan ödünçlenen sözler ise çoklukla Tuvaların "çaygıs nam üyezi” (Tek Parti Zamanı) olarak adlandırdığı dönemde, bir dil politika çerçevesinde komünist ideolojiyi dilde somutlaştırmak için kullanılan terminolojiden müteşekkildir. Bu nedenle Tuva Türkçesinde "huraangay" ya da "abbreviyatura" olarak adlandırılan ve Rusça ve Moğolca sözcüklerle kurulan kısaltmaların pek çoğu bu terminoloji ile ilgilidir.

Bildirimize konu olan kısaltmalar için öncelikle Tıva Dıldın Tayılbırlıg Slovarı (CI 2003, CII 2010), Tuvinsko-Ruskiy Slovar (Pal'mbah, 1955), Tuvinsko-Ruskiy Slovar (Tenişev, 1968), Russko- Tuvinsky Slovar (Monguş, 1980) adlı sözlüklere başvurduk ${ }^{11}$. Ayrıca Sovyetler Birliği dönemine ait başlık kısaltmaların ve karmaların tespiti için Tuva Türkçesinin yazım kılavuzunun (Orfograftıg Slovar') 1951 baskısını kullandık. Tespit edilen kısaltmaları derlemimizi "dtsearch" programı ile tarayarak örneklendirdik. Ayrıca adı geçen kısaltma türlerinin Sovyetler Birliği zamanındaki kullanımlarını ekler bölümünde çeşitli görsellerle göstermeye çalıştık. Buna göre Tuva Türkçesindeki kimi başlık kısaltmalar ve karmaların söz yapımı bağlamında, özelliklerini şöyle sıralayabiliriz:

9 Ünen (Moğ. "Gerçek”) gazetesi, 1926-1930 yılları arasında çıkarılmış, daha sonra "Şın” adını alarak günümüze kadar yayın hayatına devam etmiştir (bkz. Killi Yılmaz 2010: 178). Tuva'da yayımlanan "Şın, 70 Çıl” adlı çalışmada ,se bu gazetenin 1925 yılına kadar ayda bir ve iki sayfa olmak üzere Erge Şöleelig Tandı Tıva”, 1925 yılında ise Tıvanı Şını, 1930 yılında ise Tıva Arattıı Şını adları ile çıkarıldığı ifade edilmektedir (bkz. Çadamba (Red.) 1995: 11-13).

10 Tuva Türkçesinde Moğolcanın etkisi için bkz. Arıkoğlu, E. (2012), Tuva Türkçesinde Moğolcadan Alınan Unsurların Ses Bilgisi Açısından Durumu, Dil Araştırmaları, S. 11, ss. 17-36; Khabtagaeva, B. (2009), Mongolic Elements in Tuvan, Harrassowitz Verlag, Wiesbaden.

$11 \quad$ Tuva Türkçesi sözlükler bakımından diğer Türk lehçelerine göre şansız sayılabilir. Zira hazırlıkları 1943 yılında başlayan tek dilli ve anlatmalı Tıva Dıldın Tayılbırlıg Slovarı ilk cildi 2003, ikinci cildi 2010 yılında yayımlanmasına rağmen hala tamamlanamamıştır. Pal'bah'ın 1955, Tenişev'in 1968 ve Monguş'un 1980 yılında yayımladıkları sözlükler ise eski tarihli sözlükler olarak karşımıza çıkmaktadır. 


\section{Başlık Kısaltmalar}

SSCB döneminde kullanılmaya başlanan devlet, kurum ve kuruluş isimlerinin başlık kısaltmaları bu sahada Tuva Türkçesi ile yapılmıştıri².

APH (ARN): Arattın Revolyustug Namı, (Devrimci Halk Partisi). Rus. HPח, (HRP).

APII (ARŞ): Arattın Revolyustug Şerii, (Devrimci Halk Ordusu). Rus. HPA, (NRA).

ACCP (ASSR): Avtonomnug Sovet Sotsialista Respublika, (Özerk Sovyet Sosyalist Cumhuriyeti).

AKயI (AKŞ): Amerikanı Kattışkan Ştattarı (Amerika Birleşik Devletleri).

ГДР (GDR): German Demoktrattıg Respublika (Demokratik Alman Cumhuriyeti).

MAP (MAR): Mool Arat Respublika (Moğolistan Halk Cumhuriyeti).

СЭКП (SEKP): Sovet Evilelinin Kommunistig Partiyazı (Sovyetler Birliği Komünist Partisi), Rus. КПСС, (KPSS).

CЭTA (SETA): Sovet Evilelinin Telegraf Agentileli (Sovyetler Birliği Telgraf Ajansı) Rus. TACC, (TASS).

TAP (TAR): Tiva Arat Respublika (Tuva Halk Cumhuriyeti) Rus. THP (TNR) bkz. Resim 1 Resim 2

TAPH (TARN): Tiva Arattın Revolyustug Namı (Tuva Halk Devrimci Partisi), Rus. THPח (TNRP).

TAPЭ (TARE): Tıva Anıyaktarnın Revolyustug Evileli (Tuva Devrimci Gençler Birliği), Rus. TPCM, (TRSM).

TK (TK): Töp Komited (Merkezi Komite).

Yine bu dönemde genel olarak tüm Sovyetler Birliğinde ortak olarak kullanılan kimi Rusça başlık kısaltmalar da Tuva Türkçesi sözlüklerinde yerini almıştır:

ВЛКСМ (VLKSM): Rus. Vsesoyusnıy Leninskiy Kommunistiçeskiy Soyuz Molodeji (Sovyetler Birliği Leninist Gençlik Birliği). Tuv. Bügü-Evileldin Kommunistig Anıyaktarının Leninçi Evileli (Sovyetler Birliği Komünist Partisi Gençlik Kolu). bkz.Resim 3

ВКП(б) (VKPb): Rus. Vsesoyuznaya Kommunistiçeskaya Partiya (Bol'şevikov), (Sovyetler Birliği Komünist Partisi, Bolşevikler). Tuv. Bügü-Evileldin Kommunistig (bol'şevikter) Partiyazı. bkz. Resim 4

КУTB (KUTV): Rus. Kommunistiçeskiy Universitet Trudyaşsihsaya Vostoka (Doğu Komünist İşçiler Üniversitesi). Tuv. Çöön Çüktün Ajılçı Çonnarının Kommunistig Üniversitedi.

\footnotetext{
12 Tuva Türkçesinde başlık kısaltmaların telaffuzunda şu noktalara dikkat edilir: 1. Başlık kısaltmalarda ünsüzlere ünlü ilave edilir: РФ "eref”, АКШ “akaş/akış”, РСФСР “eresfeser”; СЭКП "sekape”. 2. Başlık kısaltmalara getirilen eklerde son hecedeki ünlü dikkate alınır: ТАР-дан “ТАR'dan, ЮНЕСКО-нуң, 'UNESCO'nuy (Biçeldey 2001: 64), (Sat ve Kunaa 2001: 24).
} 
Tuva Türkçesinde komünizm ideolojisi çerçevesinde oluşturulan kimi başlık kısaltmalar $\{+C ̧ I\}$ ekiyle genişletilmiştir:

МЧАЭ (MÇAE): Mal bolgaş Çer Ajılının Eştelgezi (Hayvancılık ve Tarım Ortak Yönetimi); МЧАЭЧИ (MÇAEÇİ): MÇAE kejigünü (MÇAE üyesi).

Tuva Türkçesi sözlüklerinde karma sözler, başlık kısaltmalara göre sayıca daha fazladır. Bu karma sözlerin özellikleri şöyle sıralanabilir¹3:

Tuva Türkçesinde karma sözler, Rusça+Rusça, Rusça+Tuvaca, Tuvaca+Rusça, Tuvaca+Tuvaca, Tuvaca+Rusça+Tuvaca, Rusça+Tuvaca+Rusça, Rusça+Tuvaca+Tuvaca yapısıyla oluşturulmuştur:

Rusça+Rusça Karma Sözler:

3ABXO3 (ZAVHOZ): Rus. Zaveduyuşiy Hozyaystvom, (Ekonomi Yönetimi).

кОЛХО3 (KOLHOZ): Rus. Kollektivnoye Hozyaistvo, (Kollektif Çalışma Çiftlikleri). bkz. Resim 5

КОМСОМОЛ (KOMSOMOL): Rus. Kommunistiçeskiy Soyuz Molodeji, (Komünist Gençler Birliği). bkz. ВЛКСМ.

HAPKOM (NARKOM): Rus. Narodnuy Komissar “Ulus Komissarı”, (Halk Komiseri).

BOEHKOMAT (VOENKOMAT): Rus. Voennıy Komissariat “Şerig Komissariadı”, (Askeri Komiser).

Rusça+Tuvaca Karma Sözler:

ПАРТАжЫЛ (PARTAJIL): Partiya Ajılı, (Parti Çalışması).

ПОЛИТАЖЫЛДАКЧЫ (POLITAJILDAKÇI): Politigtig Ajıldakçı, (Siyasi Memur)

политьИлиг (POLİTBİLİG): Politiktig Bilig, (Siyasal Bilgi).

пОЛитьөлГYМ (POLİTBÖLGÜM): Politigtig Bölgüm, (Siyasi Bölüm).

пОЛиткИЛдис (POLITKKILDİS): Politiktig Kildis, (Siyasi Şube).

ПОЛИТКИЧЭЭЛ (POLITKKIÇEEL): Politiktig Kiçeel, (Siyasi Karar).

поЛИтХОРУГДАТтЫРЫкЧЫ (POLİTHORUGDATTIRIKÇI): Politiktig Horugdattırıkçı, (Siyasi Mahkûm).

РЕВШЕРИГ (REVŞERIG): Revolyustug Şerig (Devrimci Ordu).

PEBЧAРЫШ (REVÇARIŞ): Revolyustug Çarış, (Devrimci Yarış).

Tuvaca+Rusça Karma Sözler:

${ }_{13}$ Tuva Türkçesinde karma sözler, özel isim olarak değerlendirilmez ve küçük harflerle yazılır (Sat ve Kunaa 2001: 24). 
KYPБAHK (KÜRBANK): Kürüne Bankızı, (Devlet Bankası).

КYРБЮДЖЕТ (КÜRBYUDJET): Kürüne Byüdjedi, (Devlet Bütçesi).

KYРКОМИТЕТ (KÜRKOMİTET): Kürüne Komitedi, (Devlet Komitesi).

XOOPKOM (HOORKOM): Hooray Komitedi (Şehir Komitesi).

Tuvaca+Tuvaca Karma Sözler:

КҮРСАДЫГ (KÜRSADIG): Kürüne Sadıg/Sadı, (Devlet Ticareti).

Tuvaca+Rusça+Tuvaca Karma Sözler:

APEBЭ (AREVE): Anıyaktarnıy Revolyustug Evileli, (Devrimci Gençlik Birliği).

Rusça+Tuvaca+Rusça Karma Sözler:

РАЙКYYСКОМ (RAYKÜÜSKOM): Rayonnuy Küüsekçi Komitedi (Bölge Yürütme Komitesi).

Rusça+Tuvaca+Tuvaca Karma Sözler:

РАЙХЭ (RAYHE): Rayonnuy Hereglekçiler Evileli (Bölge Tüketiciler Birliği).

Tuva Türkçesindeki bazı karma sözler, Rusça üzerinden başka dillerden ödünçlenmiştir:

PАДАР (RADAR): İng. radio detection and ranging.

ГЕСТАПО (GESTAPO): Alm. Geheime Staatspolizei.

Tuva Türkçesinde bazı karma sözler, Eski Türkçe döneminden itibaren gerek tarihsel dil alanlarında, gerek çağdaş dil alanlarında üretken olarak meslek veya uğraşı adları ile alışkanlık sıfatları türeten $\{+C ̧ I\}$ eki ile genişletilebilmektedir:

АРЕВЭЧИ (AREVEÇİ): areve+çi

РЕВАНЭЧИ (REVANEÇİ): revane+çi: devrimci gençler birliği üyesi

кОЛХОЗЧУ (KOLHOZÇU) kolhoz+çu: kolhoz işçisi

кОМСОМОЛчУ (KOMSOMOLÇU): komsomol+çu: komsomol üyesi

Tuva Türkçesinde bazı karmalar, birleşik bir ek olan fiilden isim yapım eki $\{\text {-IkçI }\}^{14}$ ile genişletilebilmektedir:

ПАРТАЖЫЛДАКЧЫ (PARTAJILDAKÇI): part-ajıl-da-kçı: parti işçisi

$14 \quad$ Ekin yapısı hakkında bkz. (İshakov, Palmbah 1961: 155). 
ПОЛИТАЖЫЛДАКЧЫ (POLİTAJILDAKÇI): polit-ajıl-da-kçı: siyasi memur

ПОЛИТХОРУГДАТТЫРЫКЧЫ (POLİTHORUGDATTIRIKÇI): polit-horug-da-ttır -lkçı: siyasi mahkûm

Tuva Türkçesinde bazı karmalar, bu sahada üretken olarak kullanılan fiilden isim yapım eki \{-(I)IşkIn\} $\}^{15}$ ile genişletilebilmektedir:

кОЛХОЗТААШКЫН (KOLHOZTAAŞKIN): kolhoz-ta-aşkın: kolhozda çalışma işi

ПОЛИтЧЫРЫДЫЫШКЫН (POLITÇ̧IRIDIIŞKIN): polit-çırı-t-ışkın: siyasi aydınlatma/eğitim.

РЕВШИМЧЭЭШКИН (REVŞIMÇEEŞKİN): rev-şimçe+eşkin: devrimci hareket

Tuva Türkçesinde bazı karmalar, Türk dilinin en üretken isimden fiil yapım eki olan $\{-\mathrm{LA}\}$ ile fiil yapılabilir. $\{-\mathrm{LA}\}$ eki ile fiilleştirilen bu karmalara aynı zamanda çatı ekleri $\{-(\mathrm{I}) \mathrm{ttIr}\},\{-\mathrm{s}\},\{-\mathrm{t}\}$ ve $\{-\mathrm{DI}\}$ getirilebilir:

3ABXO3TAAP (ZAVHOSTAAR): zavhoz+ta-: zavhozda çalış-.

ЗАВХОЗТАДЫР (ZAVHOSTADIR): zavhoz-ta-dır-: zavhozda çalıș-.

кОЛХОЗТАЖЫР (KOLHOZTAJIR): kolhoz-ta-jır-: kolhozda birlikte çalış- .

\section{ÖRNEKLER}

Areveçi kiji daalgazın kü̈̈sedip çoruur.

Areveçiler görevi yerine getirir (Tanova 2008: 33).

Bo şülüktü Tıva ASSR'nì aldarlı artizi Mariam Alekseevna Ramazanova Tiva dılga onza çugaalaar çoraan.

Bu şiiri Tuva ÖSSB’nin meşhur sanatçısı Mariam Alekseevna Ramazanova Tuvaca olağanüstü okurmuş (Kudaj1 2007: 9).

Tıvanı çonunuy suurjuy amıdıralınçe kolhoztarje şilip turar kolhozçularnıy, mçaeçilernì amıdıralını dugayında bölük şülükter bolgaş bir ballada çogaadır men.

Tuva halkının yerleşik hayatında, kolhozlarda yetişen kolhozcuların, mçaeçilerin hayatları hakkında şiirler ve balat yazacağım (İdam-Sürüy 2007: 3-4, 19).

Ol çıldarda komsomolçu anıyaktarnı mal ajılınçe haara tudar dep kıygırıg turgan.

O yıllarda komsomolcu gençleri hayvanlarla ilgili işlere göndermekle ilgili bir celp varmış (Sürün-ool 1994: 177).

15 Ekin yapısı hakkında bkz. (İshakov, Palmbah, 159). 
Revşerig paaraygı deer iyi ka’t bajı̨ bar.

Revşerig karargahı denilen iki katlı bir ev var (Sarıg-ool 2008:355).

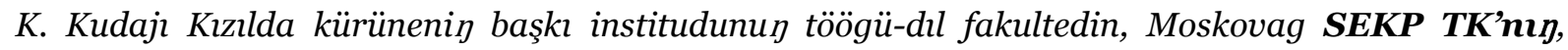
çanında Partiyanı Deedi Şkolazını jurnalistika salbırın dooskulaan.

K. Kudajı, Kızl'da Devlet Öğretmen Enstitüsünün Tarih-Dil Fakültesini, Moskova'da SBKP MK'nin yanında Parti Yüksek Okulunun Gazetecilik bölümünü bitirdi (Kudajı 1965: 2).

TARN'ga Oyun Kürsedi kandıg hamaarılgahı çoraanıl?

THDP'de Oyun Kürsedi nasıl etkili olmuştur? (Darbaa 2010: 136).

Biske zavhoz bar çüve. Hökpeş-ool dep attıg. (Monguş, CI, 2003: 576).

Bizde zavhoz var. Hökpeş-ool adında.

\section{Sonuç}

Tuva Türkçesinde başlık kısaltmalarda ve karmalarda Moğolcadan ödünçlenmiş sözcüklerin ağırlığı dikkat çekicidir: evilel (< Mŏg. eblel "birlik", Ölmez 2007: 159), kildis (< Moğ. keltes "bölüm" Ölmez, 201), kiçeel (< Moğ. kiçeyel "ders, sınıf” Ölmez,201), ajıl (< Moğ. acil "emek, çalışma”, Ölmez, 69), kürüne (< Moğ. gürün < Ma. gurun “devlet”, Ölmez, 212); Moğolcadan ödünçlenen sözcükler arasında Moğolcaya Eski Türkçe döneminde geçmiş olan ve geri ödünçleme ile Tuva Türkçesine geçen sözcükler de bulunmaktadır: bölgüm (< Mo bülgüm "grup, dernek" < ET bölük, Ölmez,99), şerig (?<Mo çerig, çirig "ordu" < ET çerig, Ölmez, 261).

Bu yapıların içerisinde partiya "parti", byüdçet "bütçe", bank "banka", komited "komite", revolyustug "devrimci" gibi Rusça sözcüklerin yanı sıra bilig (< ET bilig, bilgi, Ölmez, 95), çarış ( < ET yarış, Ölmez, 110), sadıg (<ET satıg, alış-veriş, ticaret, Ölmez, 241), çırıdıışkın (<ET yaru-, eğitim; aydınlatma, Ölmez, 119) gibi Türkçe sözcüklere de rastlanılmaktadır. Bu durum Tuva Türkçesinde devlet yönetimine ve kurumlarına, hukuka dair somut ve soyut kavramların bilhassa Moğolca ve ikincil olarak Rusça sözlerle karşılandığını göstermektedir.

Tuva Türkçesinde bazı başlık kısaltmalar ve karmalar isimden isim yapım eki $\{+C ̧ I\}$, fiilden isim yapım ekleri $\{-\mathrm{IkçI}\}$ ve $\{-(\mathrm{I}) I s ̧ \mathrm{kIn}\}$, isimden fiil yapım ekleri $\{-\mathrm{LA}\}$ ve fiilden fiil yapım ekleri $\{-(\mathrm{I}) \mathrm{ttIr}\},\{-\mathrm{s}\},\{-$ t\} ve $\{-$ DIr\} ile genişletilebilmektedir. Bu ekleri alan başlık kısaltmalar ve karmalar, Tuva Türkçesi sözlüklerinde madde başı olarak değerlendirilmiştir.

Tuva Türkçesindeki başlık kısaltmalar ve karmalar dildeki dış etki nedeniyle oluşmuş ve çoğunlukla Sovyetler Birliği döneminde dile yerleşmiş/yerleştirilmiş olan yapılardır. Tıva Dıldın Tayılbırlıg Slovarı'nda töögü "tarih" ibaresi ile gösterilen bu türden kısaltmalar, Sovyetler Birliğinin tarih sahnesinden çekilmesi ile birlikte dildeki işlevlerini yitirmeye başlamıştır. Bununla birlikte 88 yıllık ömrünün önemli bir bölümünü Sovyetler Birliği etkisi altında geçiren Tuva yazı diline ait dönem metinlerinde bu kavramların yoğun olarak kullanıldığı unutulmamalıdır. 


\section{Kisaltmalar:}

Alm. Almanca

ET Eski Türkçe

İng. İngilizce

Ma. Mançuca

Moğ. Moğolca

Rus. Rusça

Tuv. Tuva Türkçesi

\section{Kaynakça}

Akalın, Ş. H. (2015), Türkçede Söz Yapımı Yolları ve Sözlükselleşme, XI. Milli Türkoloji Kongresi Bildirileri Kitabl, 11-13 Kastm 2014, C1. S.831-841, İstanbul.

Anonim (1951), Orfograftıg Slovar', Tıva Oblastın Nom Ündürer Çeri, Kızıl.

Arıkoğlu, Ekrem (1997), Tuva Türkçesinin Tarihi Gelişimi ve Üzerinde Yapılan Çalışmalar, Türk Dünyası Dil ve Edebiyat Dergisi, S.4, s.152-161, Ankara.

Bauer, L. (2004), A Glossary of Morphology, Edinburgh University Press, Edinburgh.

Bayrav, S. (1998), Filolojinin Oluşumu, Multilingual Yabancı Dil Yayınları, İstanbul.

Biçeldey, K. A. (2001), Tiva Şın Adalganı̇ Ündezinneri, Kızıl.

Bozkurt, F., (2017), Sözlükselleşme, Genel Sözlükler İçin Sözlük Birim Seçimi, Kesit Yay., Ankara.

Beznosova, O. (2017), The Ukranian Evangelicals Under Pressure from NKVD, Ethnic and Religious Miniroties in Stalin's Soviet Union, s. 175-199, (Ed Kotljarchuk ve Sundstrom), Elendars, Stockholm.

Bussmann, H. (2006), Routledge Dictionary of Language and Linguistics, Routledge, New York and London.

Campbell, L. (1999), Historical Linguistics, An Introduction, The MIT Press, Cambridge/Massachusetts

Cannon, G. (1989), Abbreviations and Acronyms in English Word-Formation, American Speech, Vol. 64, No:2, s.99-127.

Çadamba V. F. (Red.), (1995), Respublikanı̇ Nïtilel-Politiktig Solunu, Şın, Kızıl.

Darbaa, O. (2010), Tiva Dugayında 99 Aytırıga Harnlar, Abakan.

Demirci, K. (2015), Kelime Bilgisi El Kitabı, Anı Yay. Ankara.

Eker, S. (2009), Çağdaş Türk Dili, Grafiker Yay. Ankara.

Gelderen, E. v. (2006), A History of English Language, Jean Benjamins Publishing Company, Amsterdam/Philadelphia.

Gül, R. (2017), Rus ve Türk Dilinde Kullanılan Kısaltmaların Tarihi Üzerine Bir İnceleme, İdil Dergisi, C.6, S. 30, s. 485-496.

Hendrickson, R. (2008), The Facts On File Encyclopedia of Word and Phrase Origins, Fourth Edition, Fats on File, New York.

İmer, K. (vd.) (2011), Dilbilim Sözlüğ̈̈, Boğaziçi Üniversitesi Yayınevi, İstanbul.

İshakov F. G., Palmbah, A. A. (1961), Grammatika Tuvinskogo Yazıka, Fonetika i Morfologiya, Moskva, 1961

Jablonski, S. (2005), Jablonski's Dictionary of Medical Acronyms and Abbreviations, 6th Edition, Saunders Elseiver, Philadelphia.

Karaağaç, G. (2013), Dil Bilimi Terimleri Sözlüğü, TDK Yay. Ankara. 
Kenin-Lopsan, M. (2000), Çitken Urug, Tıvanın Nom Ündürer Çeri, Kızıl.

Khabtagaeva, B. (2009), Mongolic Elements in Tuvan, Harrassowitz Verlag, Wiesbaden.

Killi Yılmaz, G. (2010), Kuzey ve Güneydoğu Sibirya Türklerinin Dil Durumu, Köksav Yay., Ankara.

Korkmaz, Z. (2007), Gramer Terimleri Sözlüğü, TDK Yay, Ankara.

Kudajı, K. K. Irjım Buluy, Tıvanın Nom Ündürer Çeri, Kızıl.

Kudajı, K. K. (2007), Bistiø Üyeniฤ Maadırı, Tıvanıy Yu. Ş. Kyünzegeş Attıg Nom Ündürer Çeri, Kızıl.

Malmkjær, K. (2002), The Linguistics Encyclopedia, Second Edition, Routledge, London/New York.

Monguş, D. A. (Red.), (1980), Russko-Tuvinsky Slovar, Moskva.

Monguş, D. A. (Red.), (2003), Tiva Dıldın Tayılbırlıg Slovarı, CI, Nauka, Novosibirsk.

Monguş, D. A. (Red.), (2011), Tiva Dıldıy Tayılbırlıg Slovarı, CII, Nauka, Novosibirsk.

Ölmez, M. (2007), Tuwinischer Wortschatz Mit Alttürkischen Und Mongolischen Parallelen / Tuvacanin Sözvarlı̆̆ - Eski Türkçe Ve Moğolca Denkleriyle”, Harrassowitz Verlag, Wiesbaden.

Öztürk, S. (1994), Osmanl Arşiv Belgelerinde Siyakat Yazısı ve Tarihi Gelişimi, Başbakanlık Devlet Arşivleri Genel Müdürlüğü, Osmanlı Arşivi Daire Başkanlığı Yay., Ankara.

Palmbah, A. A. (1955), Tuvinsko-Russkiy Slovar, Moskva.

Partridge, E. (2006), Origins, A Short Etymological Dictionary of Modern English, Routledge, London/New York.

Rajimwale, S. (2006), Handbook of Linguistic Terms, Sarup and Sons, New Delhi.

Raistrick, D. (2008), Index to Legal Citations and Abbreviations, Sweet and Maxwell, London.

Richards J. C., Schmidt R. (2002), Dictionary of Language, Teaching and Applied Linguistics, Longman.

Rigdon, J. C., (2016), Dictionary of Computer Acronyms and Abbreviations, Volume 2

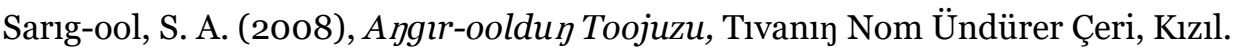

Sat, Ş. Ç., Salzııma E. B. (1980), Amgı Tıva Literaturalıg Dıl, Kızıl.

Sat, Ş. Ç. ve Kunaa, A. Ç. , (2001), Tıva Orfografiyanı Bolgaş Punktuatsiyanı Dürümneri, Kızll.

Sürün-ool, S., (1994), Tıvalaar Kuuskun, Tıvanın Nom Ündürer Çeri, Kızıl.

Tanova, E. T. (2008), Kara-Bay, Tıvanın Yu. Ş. Kyunzegeş Attıg Nom Ündürer Çeri, Kızıl.

Tenişev, E. R. (1968), Tuvinsko-Russkiy Slovar, İzdatel'stvo, Sovyetskaya Ensiklopediya, Moskva.

Vardar, B. (2002), Dilbilim Terimleri Sözlüğü, Multilingual Yabancı Dil Yayınları, İstanbul.

İdam-Sürüy, (2007), Çoptun-ool Oglu Çoçagar, Ulug Hem, Tiva Çogaalçılarnıı Setküülü, No:3-4, s. 334, Kizıl.

Yıldız, H. (2010), Türk Dilinde Kısaltmalar Üzerine Bir İnceleme: Uzun Lafın Kısası, Müjgan Cunbur Armağan,, TKAE Yay., s. 259-282, Ankara.

\section{Eklerin Alındığı Kaynaklar}

Resim 1: Lamina, V. A. (Red.), (2007), Istoriya Tuvı, C2, s. Kapak sayfası, Nauka, Novosibirsk.

Resim 2: Lamina, V. A. (Red), (2007), Istoriya Tuvı, C2, s. 212, Nauka, Novosibirsk.

Resim 3: Erişim Tarihi: 22.05.2018, Публикации наших сотрудников https://ioe.hse.ru/ds/news/188940049.html

Resim 4: Erişim Tarihi: 22.05.2018, komsomolskij znachok, http://falerist.org/znaki/komsomolskijznachok.html 
$\mathbf{1 7 6}$ / RumeliDE Journal of Language and Literature Studies 2018. Special Issue 4 (August)

Tuva Türkçesinde Başlık Kısaltmalar ve Karmalar / İ. Tosun (p. 162-178)

Resim 5: Erişim Tarihi: 22.05.20: 5 Ocak 1930: Sovyetler Birliği'nde tarımın kolektivizasyonu yasası çıarıldı: $\quad$ http://gazetemanifesto.com/2018/01/05/hafiza-i-beser-5-ocak-1930-sovyetlerbirliginde-tarimin-kolektivizasyonu-yasasi-cikarildi/

\section{Ekler}

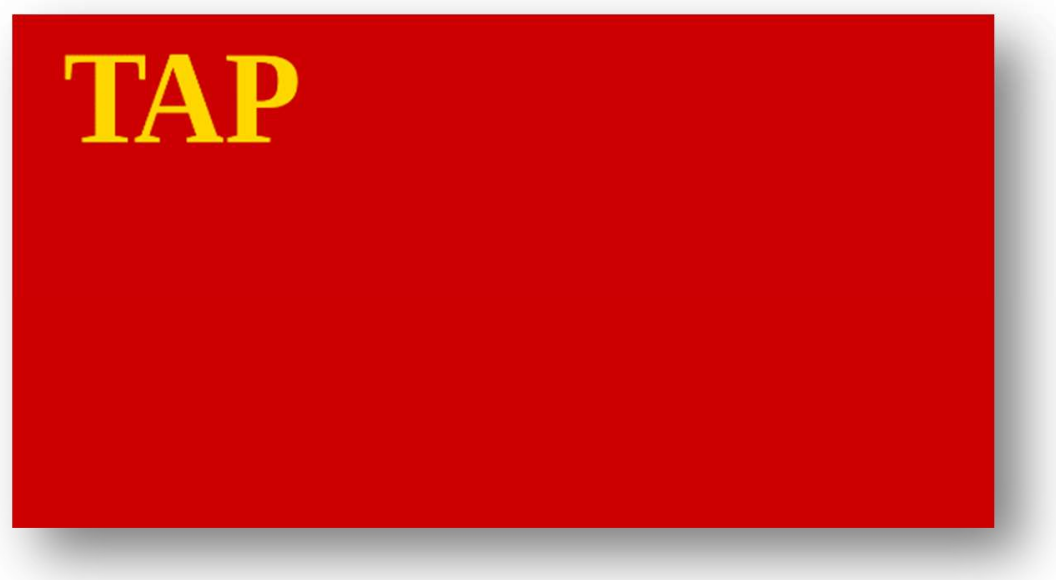

Resim 1: TAR: Tiva Arat Respublika

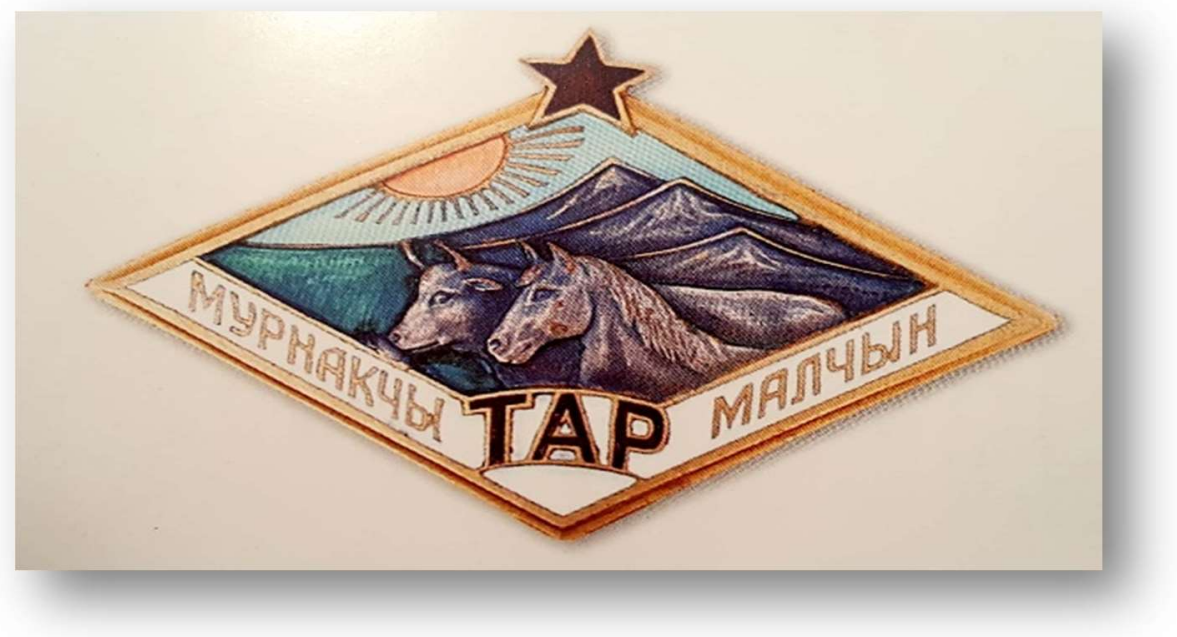

Resim 2: TAR: Tıva Arat Respublika, Murnakçı (Öncü), Malçın (Malcı) 


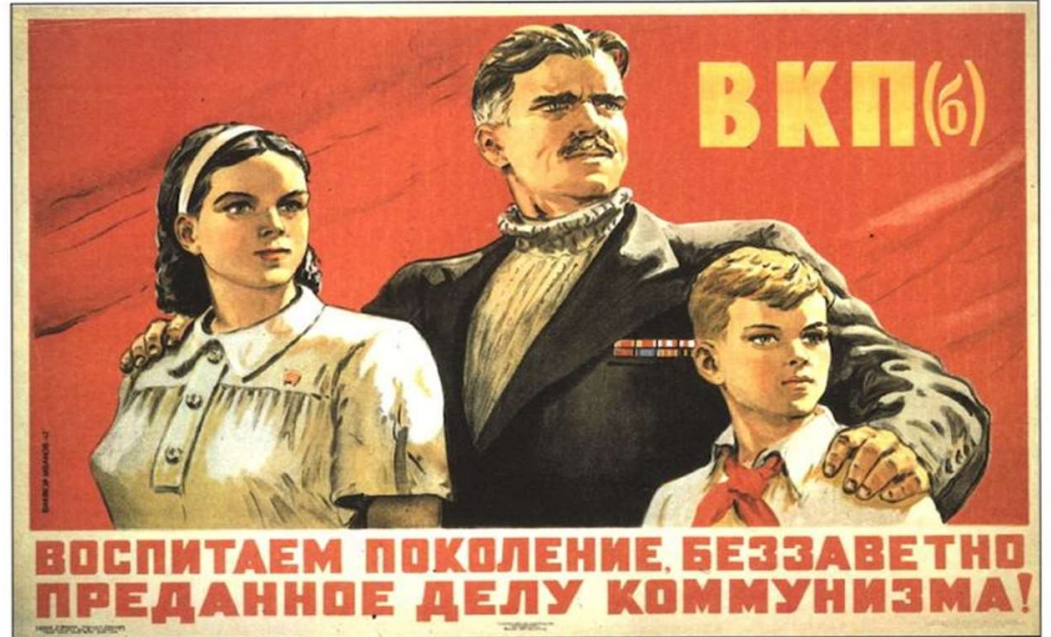

Resim 3: ВКП(б): Sovyetler Birliği Komünist Partisi

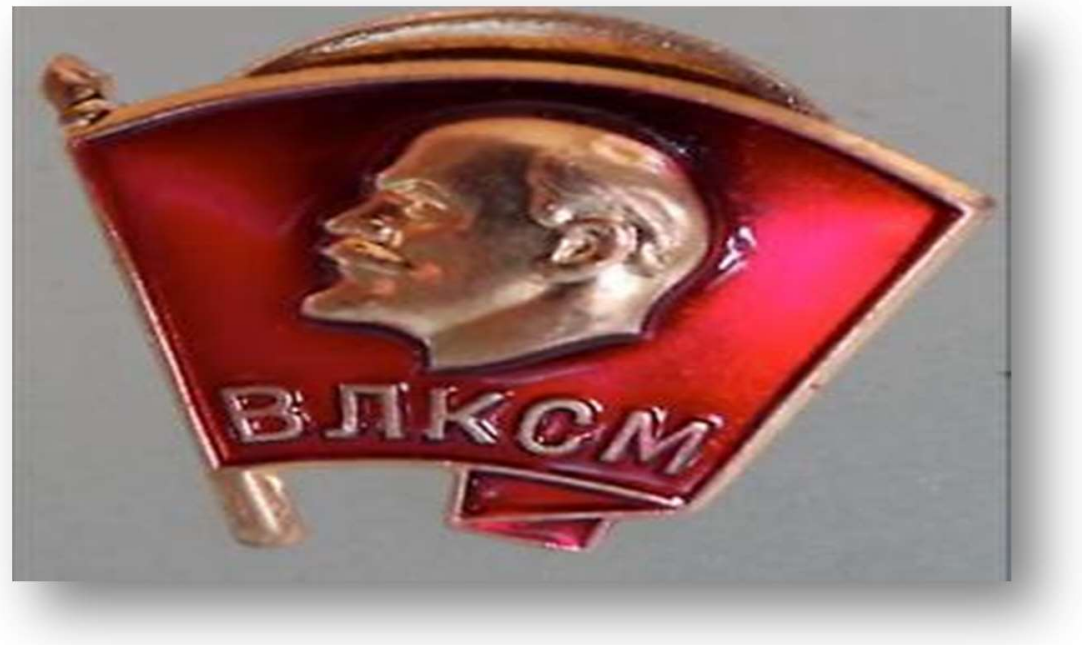

Resim 4: ВЛКСМ: Sovyetler Birliği Leninist Gençler Birliği 
178 / RumeliDE Journal of Language and Literature Studies 2018. Special Issue 4 (August)

Tuva Türkçesinde Başlık Kısaltmalar ve Karmalar / İ. Tosun (p. 162-178)

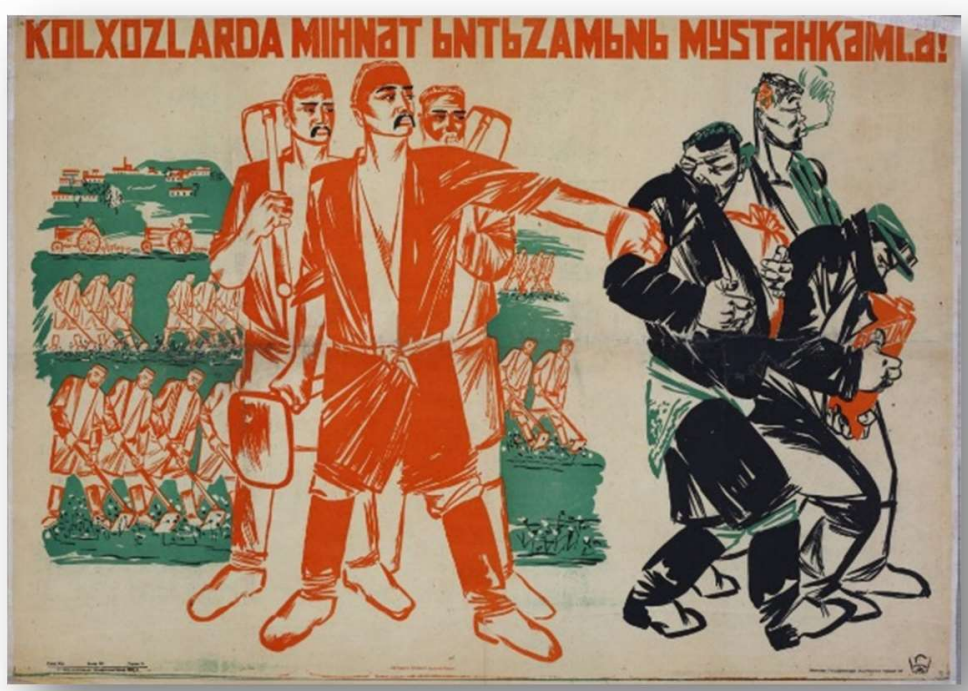

Resim 5: кОЛхо3: Kolektif Çalışma Çiftliği 